\title{
Quality and safety evaluation of new tomato cultivars
}

\author{
Mattia Rapa*, Salvatore Ciano, Laura Gobbi, Roberto Ruggieri and Giulina Vinci \\ Department of Management, Sapienza University of Rome, via del Castro Laurenziano 9, 00161, Rome, Italy
}

*Corresponding Author: Mattia Rapa, Department of Management, Sapienza University of Rome, via del Castro Laurenziano 9, 00161, Rome, Italy. Email: mattia.rapa@uniroma1.it

Received: 17 May 2020; Accepted: 12 March 2021; Published: 7 April 2021

(c) 2021 Codon Publications

\section{OPEN ACCESS (C) (1) (2)}

PAPER

\begin{abstract}
This paper is aimed to provide a quality and safety assessment of new cherry tomato cultivars (Solanum Lycopersicum var. cerasiforme): Bamano, Dulcemiel, and Sugarland. Eight biogenic amines, total phenolics, total carotenoids, lycopene, and antioxidant activity (2,2-diphenyl-1-picrylhydrazyl [DPPH] and 2,2-azino-bis (3-ethylbenzo thiazoline-6-sulfonic acid) diammonium salt [ABTS] assays) were determined. Comparison with control cultivars demonstrated lower $\mathrm{pH}$ values, and total contents of biogenic amines and antioxidant compounds while having higher soluble solid concentration. Moreover, multivariate statistical analyses (principal component analysis and cluster analysis) were applied to the results. Different results allowed for a successful differentiation of new cultivars. Therefore, the chosen compounds resulted in suitable markers for quality and safety assessment of tomatoes.
\end{abstract}

Keywords: antioxidants, biogenic amines, carotenoids, food safety and quality, phenolics, tomato

\section{Introduction}

Tomato (Solanum Lycopersicum) is an annual plant whose berries are used widely, either processed or raw, for food and beverage. Tomato plants are native to South America, and their cultivation in the Mediterranean countries dates back to the 17th century (Peralta and Spooner, 2014). Italy is the first tomato-producing country in Europe and one of the top 10 producers in the world (Food and Agriculture Organization Corporate Statistical Database [FAOSTAT], 2019). Italy also tops the list for global export of processed tomatoes ahead of China (Istituto Servizi Mercato Agricolo Alimentare, 2017). In Italy, tomatoes are cultivated especially in the central and southern regions, where small-size tomato varieties are much appreciated (Masetti et al., 2014; Carillo et al., 2019). Tomato is of great value in the global vegetable consumption, and recently, there has been an increase in the spread of new small-size tomato cultivars. Small-size tomatoes are preferred for fresh consumption than regular-size tomatoes, and consumers choose the same for their organoleptic proprieties (Liu et al., 2019). Tomato is one of the most studied crops, and their genetic improvement is constant. The breeding programs led to the offspring of new varieties that can meet the industry and/or consumer preferences.

Moreover, through new cultivars, disease resistance is achieved. Recently, new hybrid cultivars of tomatoes named Bamano, Dulcemiel, and Sugarland have been introduced in Central Italy. These cultivars are trying to expand the fresh agronomic market with products characterized by unique organoleptic and nutritional properties. Usually, seed companies evaluate prime properties (e.g., size, color, sugars, etc.) under different stress and environmental conditions, followed by researchers' early characterization (Ingallina et al., 2020c). However, in order to valorize the final product, quality and safety assessment is highly recommended. Quality assessment is necessary to determine molecular markers, typical of 
a sample, that can establish the sample's origin or the good state of storage (Giuggioli et al., 2016). Antioxidant compounds are usually used to evaluate food quality (Armenta and de la Guardia, 2016). Phenolic compounds, secondary metabolites of many plants, are ubiquitous in the vegetable domain and they are one of the most extensively studied groups of natural compounds. Their dietary intake is highly recommended, and they have anti-microbial and anti-carcinogenic effects (CoyagoCruz et al., 2018). These compounds have already been detected in good quantity in commercial tomatoes, especially in small-size varieties (Selli et al., 2014). Tomatoes have a significant antioxidant activity afforded by phenolic compounds and antioxidants such as carotenoids, lycopene, and vitamins (Szabo et al., 2018). Total phenolic content, 2,2-diphenyl-1-picrylhydrazyl (DPPH), and 2,2-azino-bis (3-ethylbenzothiazoline-6-sulfonic acid) diammonium salt (ABTS) assays are established as quick and robust tools for characterizing antioxidants in the fractions of hydrophilic tomatoes. They are used widely in an explorative and preliminary assessment of vegetables and fruits (Fanasca et al., 2006; Preti et al., 2017). Besides, to characterize the antioxidants present in the lipophilic fraction, such as carotenoids (including lycopene), Ultraviolet-Visible spectroscopy (UV-Vis) methods are used generally (Ingallina et al., 2020a).

Other metabolites present in small amounts in food are often used as markers of food safety. Among these compounds, biogenic amines (BAs) are widely used as food safety markers because of their presence in food and their effect on the human body. BAs are the result of the decarboxylation of amino acids, but their presence in food can also be related to spoilage. In addition, BAs can induce several negative physiological reactions, and the investigation of their levels in food is important for consumers' health and the formulation of diets (Kalač, 2014). Some BAs, such as histamine (HIS) and tyramine (TYR), pose potential risks to human health, that is, 'scombroid food poisoning' and 'cheese crisis' (Al Bulushi et al., 2009). However, not all BAs are dangerous for human health. For example, serotonin (SER) plays an essential role to regulate mood, sleep, body temperature, sexuality, and appetite in the central nervous system (Hano et al., 2017). Therefore, its presence in food could be an exciting feature. Notwithstanding that presence of BAs is regulated in some foods and drinks, some authors have suggested BAs to be food quality markers (Silla Santos, 1996).

In this work, a quality and safety assessment of three new tomato cultivars is proposed. At first, soluble solid concentration (SSC) and $\mathrm{pH}$ were determined to evaluate physicochemical characteristics of the tomato cultivars. Thereafter, an evaluation of antioxidants present in hydrophilic and lipophilic fractions was carried out. The hydrophilic antioxidant fraction was tested by in vitro antioxidant activity through scavenging of DPPH- and ABTS-free radicals and total phenolic content by the Folin-Ciocâlteu method. Total contents of carotenoids and lycopene were analyzed in lipophilic fraction by UV-Vis methods.

Moreover, the profile of eight BAs was evaluated in tomato samples by high-performance liquid chromatography with fluorescence detection (HPLC-FD) after dansyl chloride derivatization. The BAs studied were spermine (SPM), spermidine (SPD), putrescine (PUT), and cadaverine (CAD) for polyamines, whereas $\beta$-phenylethylamine ( $\beta$-PEA), HIS, SER, and TYR were studied for monoamines. The above-mentioned analyses were also conducted on samples from two traditional cultivars of tomatoes used for fresh market and canning industry.

Finally, a multivariate statistical analysis (principal component analysis [PCA] and cluster analysis [CA]) was conducted on the bioactive compound profiles of tomatoes to highlight natural differentiation of samples coming from the new cultivars.

\section{Materials and methods}

\section{Materials}

Methanol $\left(\mathrm{CH}_{3} \mathrm{OH}\right)$, n-Hexane $\left(\mathrm{C}_{6} \mathrm{H}_{14}\right)$, water (HPLC grade), acetonitrile (HPLC grade), Folin-Ciocâlteu reagent $\left(\mathrm{H}_{3}\left[\mathrm{P}\left(\mathrm{W}_{3} \mathrm{O}_{10}\right)_{4}\right] / \mathrm{H}_{3}\left[\mathrm{P}\left(\mathrm{Mo}_{3} \mathrm{O}_{10}\right)_{4}\right]\right)$, ABTS, DPPH, potassium persulfate, sodium bicarbonate $\left(\mathrm{NaHCO}_{3}\right)$, gallic acid $\left(\mathrm{C}_{7} \mathrm{H}_{6} \mathrm{O}_{5}\right)$, perchloric acid $\left(\mathrm{HClO}_{4}\right)$, sodium hydroxide $(\mathrm{NaOH})$, sodium carbonate $\left(\mathrm{Na}_{2} \mathrm{CO}_{3}\right)$, and ammonium hydroxide $\left(\mathrm{NH}_{4} \mathrm{OH}\right)$ were purchased from Sigma Aldrich Chemical Co. The eight BAs-HIS, SER, SPM, SPD, PUT, $\beta$-PEA, CAD, and TYR-were supplied by Supelco (Bellefonte, PA, USA) as well as the derivatizing agent, dansyl chloride, and the internal standard, 1,7-diaminoheptane (IS).

\section{Sampling}

Tomato samples were supplied by eight different farmers with similar pedo-climatic conditions, located in the south of Lazio region (Italy), which were harvested in 2016. Tomato seeds (Bamano and Dulcemiel) were supplied by Syngenta, Basel, Switzerland and Rijk Zwaan, De Lier, The Netherlands (Sugarland). Two samplings per cultivar were prepared for each farm. A total of 48 samples were collected (Bamano, $\mathrm{n}=16$; Dulcemiel, $\mathrm{n}=$ 16; and Sugarland, $\mathrm{n}=16$ ). Moreover, other 11 samples were collected from selected cultivars for fresh market and canning industry. After acquisition, samples were 
Table 1. Physical characteristics of new tomato cultivars.

\begin{tabular}{llll}
\hline Cultivar & Color & Size & Fruit weight \\
\hline Bamano & Bright orange & $\begin{array}{l}\text { Elongated shape } \\
(2.5 \pm 0.5 \times 4.5 \pm 0.5 \mathrm{~cm})\end{array}$ & $11 \pm 1 \mathrm{~g}$ \\
Dulcemiel & Green with honey shades & $\begin{array}{l}\text { Round shape } \\
(2.5 \pm 0.5 \times 3.5 \pm 0.5 \mathrm{~cm})\end{array}$ & $15 \pm 1 \mathrm{~g}$ \\
Sugarland & Deep shiny red & $\begin{array}{l}\text { Round shape } \\
(1.5 \pm 0.5 \times 2.5 \pm 0.5 \mathrm{~cm})\end{array}$ & $12 \pm 1 \mathrm{~g}$ \\
& & & \\
\hline
\end{tabular}

homogenized by an Ultra-Turrax system and stored at $-18^{\circ} \mathrm{C}$. The physical characteristics of each cultivar are reported in Table 1.

\section{Physicochemical parameters}

The SSC was determined with a portable refractometer (RS PRO; Milan, Italy) at $20^{\circ} \mathrm{C}$ and expressed as ${ }^{\circ}$ Brix. The $\mathrm{pH}$ was measured with a $\mathrm{pH}$-meter (Hach Company; Loveland, CO, USA).

\section{Determination of Biogenic Amines}

\section{Extraction}

Biogenic amines were extracted according to a previously optimized tomato products method (Chiacchierini et al., 2006). About $8 \mathrm{~g}$ of sample, previously added with $0.1 \mathrm{~mL}$ of IS $(100 \mathrm{mg} / \mathrm{L})$, was extracted with $10 \mathrm{~mL}$ of $0.6 \mathrm{M} \mathrm{HClO}_{4}$, homogenized for $3 \mathrm{~min}$, and centrifuged at $2,700 \mathrm{~g}$ for $10 \mathrm{~min}$. The supernatant was filtered through a $0.20-\mu \mathrm{m}$ membrane Millipore filter and collected in a flask. The residue was added with $10 \mathrm{~mL}$ of $0.6 \mathrm{M} \mathrm{HClO}_{4}$, mixed, and again centrifuged for $10 \mathrm{~min}$. Then the second extract was filtered and added to the first one. The final volume was adjusted to $25 \mathrm{~mL}$ with $0.6 \mathrm{M} \mathrm{HClO}_{4}$.

\section{Derivatization}

An aliquot of $1 \mathrm{~mL}$ of the final extract was derivatized according to procedures reported by Ingallina et al. (2020b). About $200 \mu \mathrm{L}$ of $2 \mathrm{M} \mathrm{NaOH}, 300 \mu \mathrm{L}$ of saturated $\mathrm{NaHCO}_{3}$ solution, and $2 \mathrm{~mL}$ of dansyl chloride solution (10 $\mathrm{mg} / \mathrm{mL}$ in acetone) were added in a tube. After shaking, the samples were left in dark for $60 \mathrm{~min}$ at $45^{\circ} \mathrm{C}$. About $100 \mu \mathrm{L}$ of $25 \% \mathrm{NH}_{4} \mathrm{OH}$ was added to stop the derivatizing reaction. The final volume was adjusted to $5 \mathrm{~mL}$ by adding acetonitrile. The dansylated extract was filtered using 0.22- $\mu \mathrm{m}$ filter (Polypro Acrodisc, Pall Gelman Laboratory, USA) and injected into the HPLC system (Ingallina et al., 2020b).

\section{Chromatographic setup}

Chromatographic separation was achieved by a system consisting of a LC-10 ATVP binary HPLC pump, a Supelcosil LC-18 column (Supelco, 5- $\mu \mathrm{m}$ particle size, $150 \times 2.1-\mathrm{mm}$ I.D.) equipped with a Supelguard LC-18 guard column (Supelco Inc., Bellefonte, PA, USA), and an RF-10AXL fluorescence detector (Shimadzu, Kyoto, Japan). The injector was fitted with a $20-\mu \mathrm{L}$ loop. The chromatographic data were collected and processed using Class-VP software (Shimadzu). The analysis was conducted as described in previous work. Fluorescence detection was set at $320 \mathrm{~nm}$ for excitation and $523 \mathrm{~nm}$ for emission. Identification of the BAs was based on their retention time and adding of standards. The quantification was performed using the internal standard calibration method by linear regression analysis $\left(R^{2}>0.995\right)$.

\section{Extraction of hydrophilic antioxidant compounds}

Sample extractions for antioxidant activity and total phenolic content were prepared from $2 \mathrm{~g}$ of tomatoes in 20 $\mathrm{mL}$ of methanol. Samples were homogenized in an UltraTurrax for $3 \mathrm{~min}$ and centrifuged at 2,400 $\mathrm{g}$ for $5 \mathrm{~min}$ (Fratoddi et al., 2018).

\section{Determination of total phenolic content (Folin-Ciocâlteu)}

Total Phenolic Content (TPC) was determined using the Folin-Ciocâlteu method (Fratoddi et al., 2018), modified for tomatoes as follows: $1 \mathrm{~mL}$ of methanolic extract was 
added to $0.25 \mathrm{~mL}$ of Folin-Ciocâlteu reagent and $0.5 \mathrm{~mL}$ of $\mathrm{Na}_{2} \mathrm{CO}_{3}$ water solution $(7.5 \% \mathrm{w} / \mathrm{v})$ in a $10-\mathrm{mL}$ volumetric flask. The final volume was reached with purified water. Spectrophotometric analysis was performed at $\lambda=750 \mathrm{~nm}$ after 45 min of incubation in dark at room temperature. TPC was expressed as milligrams of gallic acid equivalent (GAE) per kg. The final results were obtained through a calibration curve ranging from 15 to $500 \mathrm{mg} / \mathrm{L}\left(R^{2}=0.9925\right)$.

\section{Determination of antioxidant activity}

The DPPH and ABTS assays were based on the same mode of action, and they are common in vitro antioxidant tests (Tonolo et al., 2019). The disappearance of radical was determined by measuring absorbance at 515 $\mathrm{nm}(\mathrm{DPPH})$ and $734 \mathrm{~nm}$ (ABTS) as described previously (Preti et al. 2017); the absorbance was measured in 1-cm path length cuvettes, using a UV-Vis spectrophotometer (Jenway, Stone, UK).

Results were expressed as inhibition rate and were calculated based on Equation 1:

$$
\mathrm{I} \%=\frac{\mathrm{A}_{0}-\mathrm{A}_{\mathrm{f}}}{\mathrm{A}_{0}} \times 100,
$$

where $A_{0}$ is the radical cation's initial absorbance, and $A_{\mathrm{f}}$ is the absorbance after the addition of sample extract.

\section{Lipophilic antioxidant extraction}

Briefly, $7 \mathrm{~mL}$ of ethanol:hexane mixture $(4: 3 \mathrm{v}: \mathrm{v})$ was added to $0.1-\mathrm{g}$ homogenized sample in a glass tube (protected from light). The lycopene extraction was conducted by agitating the mixture for $1 \mathrm{~h}$ (darkness) at 200 $\mathrm{rpm}$. Thereafter, $1 \mathrm{~mL}$ of distilled water was added to the mixture and stirred by inversion. The hexane fraction was then collected in an amber vial.

\section{Total carotenoids}

The total carotenoid content was determined at $449 \mathrm{~nm}$ (Ingallina et al., 2020a). The results were compared with a standard solution of $\beta$-carotene in $n$-hexane, and the quantification of total carotenoids was achieved by the linear regression $\left(r^{2}=0.9962\right)$ and expressed as milligram of $\beta$-carotene (mg BCE).

\section{Lycopene determination}

The lycopene determination was performed by measuring the hexane phase absorbance at $472 \mathrm{~nm}$ in a spectrophotometer. The lycopene content was calculated with the Lambert-Beer Law as described in Equation 2:

$$
\text { Lycopene }(\mathrm{mg} / \mathrm{kg})=\frac{\mathrm{Abs} \times \mathrm{MW} \times 2.7}{\mathrm{w} \times \mathrm{E}} \text {, }
$$

where $A b s$ is the absorbance reading, $M W$ is the molecular weight, 2.7 refers to the volume (in $\mathrm{mL}$ ) of the hexane phase, $w$ is the sample weight, and $E$ is the molar extinction coefficient of lycopene in hexane $(185.3 \mathrm{mM} / \mathrm{cm})$. Results were expressed as $\mathrm{mg} / \mathrm{kg}$ of lycopene (fresh weight, FW) (Antolinos et al., 2020).

\section{Statistical analysis}

All the experiments were conducted in triplicate and expressed as mean \pm standard deviation. T-test, correlations, and chemometric data analyses (PCA and CA) were performed with JMP software (ver. 15.2, SAS Institute, Cary, NC, USA).

\section{Results and discussion}

\section{Physicochemical properties}

The presence of phytochemicals in tomatoes, such as carotenoids and phenolic compounds, mineral salts, and organic and fatty acids content is closely related to their health-promoting properties. Therefore, these are used in quality and safety assessment. These compounds are biosynthesized and accumulated in fruits, and their content is influenced by environmental factors, cultural practices, and genetic aspects, such as different cultivars (Antolinos et al., 2020). In this respect, $\mathrm{pH}$ and SSC were evaluated in the examined samples, and the results are reported in Figure 1. The new cultivar samples had significantly lower $\mathrm{pH}$ values $(P<0.01)$ compared to control cultivars, even if the difference was $8-10 \%$. These results suggest a possible use of specific consumers satisfaction related to their organoleptic and sensorial features. Moreover, the highest SSC was found for Sugarland cultivar, followed by Bamano and Dulcemiel. The resulting SSC values of new cultivars were statistically different from that of the control, indicating greater soluble solid compounds.

\section{Biogenic amines}

The evaluation of BAs in fresh vegetables has been recently explored in literature, tomatoes included (Sánchez-Pérez et al., 2018). According to SánchezPérez et al. (2018), the BAs found in tomatoes were HIS (n.d.-22 mg/kg FW); TYR (n.d.-6.38 mg/kg FW); PUT (5.3-35.5 mg/kg FW), and CAD (n.d.-2.33 mg/kg FW).

In this study, contents of eight BAs were determined in three new cultivars of cherry tomatoes; their profiles are shown in Figure 2.

The chromatograms exhibited different trends for the three cultivars. An appreciable peak resolution was achieved (Palomino-Vasco et al., 2019; Ramos et al., 


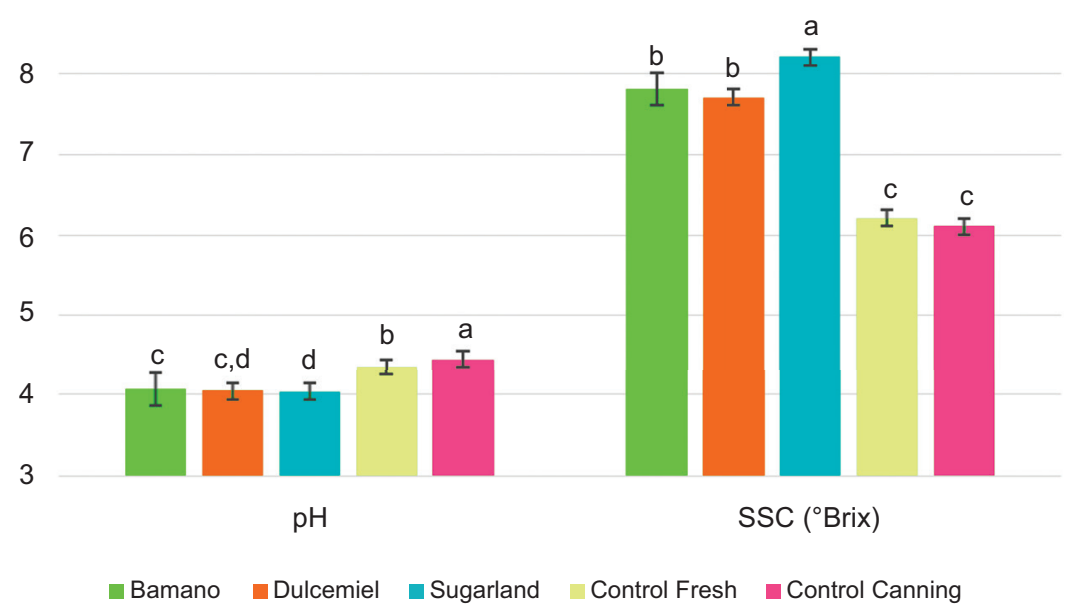

Figure 1. Determination of physicochemical properties of different tomato cultivars: $\mathrm{pH}$ and soluble solid concentration (SSC) ('Brix). Samples not connected by the same letter are significantly different.

2020). The quantification of BAs in new cultivars and control tomatoes is summarized in Table 2. Table 2 also describes the T-test results $(\alpha=0.95)$ of each variable for the five categories of the sample analyzed.

Among new cultivars, the highest total BA contents in tomatoes was determined in Sugarland $(275.2 \pm 11.10 \mathrm{mg} /$ $\mathrm{kg})$, followed by Dulcemiel $(201.01 \pm 1.71 \mathrm{mg} / \mathrm{kg})$ and Bamano $(137.36 \pm 1.98 \mathrm{mg} / \mathrm{kg})$. These contents were comparable with the control canning cultivar, in spite of the fact that the fresh control had a higher total BA values.

The amount of HIS, PUT, and CAD of the new cultivars (<LOQ: $0.57 \mathrm{mg} / \mathrm{kg}, 0.16-5.75 \mathrm{mg} / \mathrm{kg}$, and $1.15-2.41 \mathrm{mg} /$ $\mathrm{kg}$, respectively) was in agreement with results from literature, while TYR was below the limit of quantification for all the samples. Compared with the control cultivars, the HIS values were comparable with that of the canning cultivar and were lower than that of the fresh cultivar

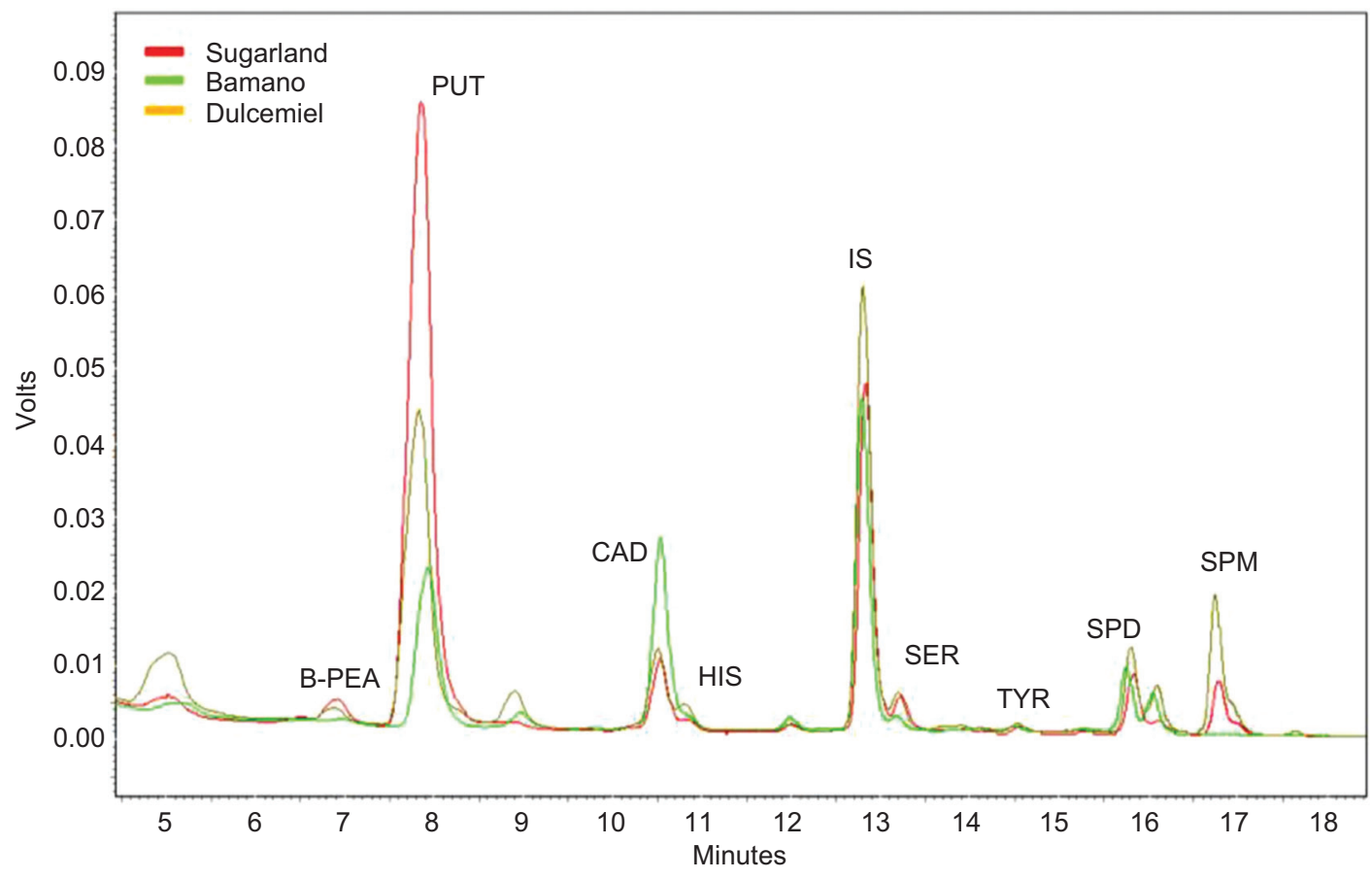

Figure 2. Chromatographic profiles of biogenic amines determined in tomato samples: Sugarland (red trace), Bamano (green trace), and Dulcemiel (dark yellow trace). $\beta$-PEA: $\beta$-phenylethylamine; PUT: putrescine; CAD: cadaverine; HIS: histamine; IS: internal standard; SER: serotonin; TYR: tyramine; SPD: spermidine; and SPM: spermine. 
Table 2. Quantitative results of biogenic amines in tomato samples ( $\mathrm{mg} / \mathrm{kg})$. Samples not connected by the same letter are significantly different.

\begin{tabular}{|c|c|c|c|c|c|}
\hline & Bamano & Dulcemiel & Sugarland & Control fresh & Control canning \\
\hline$\beta$-PEA & $1.16^{b} \pm 0.05$ & $0.17^{c} \pm 0.001$ & $0.17^{c} \pm 0.01$ & $1.47^{a} \pm 0.12$ & $1.13^{b} \pm 0.10$ \\
\hline PUT & $0.16^{c} \pm 0.01$ & $0.56^{c} \pm 0.03$ & $5.75^{b} \pm 0.14$ & $11.17^{\mathrm{a}} \pm 4.17$ & $4.98^{b} \pm 0.21$ \\
\hline CAD & $2.41^{a} \pm 0.09$ & $1.15^{b} \pm 0.01$ & $1.22^{b} \pm 0.02$ & $0.94^{c} \pm 0.15$ & $0.70^{d} \pm 0.03$ \\
\hline HIS & $<\mathrm{LOQ}^{\mathrm{c}}$ & $0.57^{\mathrm{a}, \mathrm{b}} \pm 0.02$ & $0.33^{b, c} \pm 0.01$ & $1.01^{a} \pm 0.41$ & $0.10^{b, c} \pm 0.06$ \\
\hline SER & $132.47^{d} \pm 2.05$ & $197.27^{c} \pm 1.71$ & $266.87^{b} \pm 11.16$ & $379.51^{a} \pm 4.06$ & $146.81^{c, d} \pm 8.67$ \\
\hline TYR & $<\mathrm{LOQ}^{\mathrm{c}}$ & $<\mathrm{LOQ}^{\mathrm{C}}$ & $<\mathrm{LOQ}^{\mathrm{c}}$ & $1.29^{a} \pm 0.09$ & $0.67^{b} \pm 0.08$ \\
\hline SPD & $0.29^{b} \pm 0.01$ & $0.37^{b} \pm 0.02$ & $0.33^{b} \pm 0.01$ & $8.32^{\mathrm{a}} \pm 0.40$ & $8.32^{\mathrm{a}} \pm 0.85$ \\
\hline SPM & $0.87^{b} \pm 0.04$ & $0.91^{b} \pm 0.06$ & $0.53^{c} \pm 0.02$ & $0.80^{b, c} \pm 0.03$ & $1.16^{\mathrm{a}} \pm 0.47$ \\
\hline Total BAs & $137.36^{d} \pm 1.98$ & $201.01^{c} \pm 1.71$ & $275.2^{b} \pm 11.10$ & $404.53^{a} \pm 9.45$ & $164.67^{c, d} \pm 10.53$ \\
\hline
\end{tabular}

$\beta$-PEA: $\beta$-phenylethylamine; PUT: putrescine; CAD: cadaverine; HIS: histamine; SER: serotonin; TYR: tyramine; SPD: spermidine; SPM: spermine; total BAs: total biogenic amines; LOQ: limit of quantification.

$(1.01 \pm 0.41 \mathrm{mg} / \mathrm{kg})$. Besides, in the control cultivar, TYR was also observed $(0.67-1.29 \mathrm{mg} / \mathrm{kg})$. It is essential to underline BAs' shallow levels such as HIS and TYR, frequently reported as dangerous in the human diet (Linares et al., 2016). Although, the HIS and TYR contents were not dangerous, a lower concentration in new cultivars allowed products with lesser contamination at the processing stage.

Polyamines, such as SPD and SPM, play a role in increasing shelf life of tomatoes. The gene expression related to SPD and SPM would reduce the post-harvest senescence and decay (Handa and Mattoo, 2010; Nambeesan et al., 2010). Thereafter, the low amount of SPD $(0.29-0.37 \mathrm{mg} / \mathrm{kg})$ and SPM $(0.53-0.91 \mathrm{mg} / \mathrm{kg})$ found in all new cultivars could be a desirable feature. They could be related to a natural over expression of some metabolic pathways in these cherry tomato varieties, contributing to the elongation of shelf life. Also, the lowest concentrations in new cultivars, compared to the control, suggest these tomato cultivars' eligibility in the supply chain.

Finally, an interesting remark should be made about the SER content. The SER content was the major contributor to the total contents of BAs established in the samples, starting from $132.47 \pm 2.05 \mathrm{mg} / \mathrm{kg}$ (96\%) for Bamano to $197.27 \pm 1.71 \mathrm{mg} / \mathrm{kg}(98 \%)$ for Dulcemiel and $266.87 \pm$ $11.16 \mathrm{mg} / \mathrm{kg}$ (97\%) for Sugarland. These results were in agreement with already published results (Riga et al., 2016). A similar trend in SER content was also found in control cultivars (90-93\%), although in slightly lower proportions. However, the excellent SER content in tomato fruits is related to its several physiological functions in plants (e.g., growth regulator, protection against pathogens, etc.). In plants, SER is produced from tryptophan, and demonstrates some positive effects on the human body. Daily assumption of SER-rich vegetable varieties has demonstrated, inter alia, useful anti-obesity and anxiety control effects (Islam et al., 2016). Moreover, it has been proved that the SER content tends to decrease in processed tomato products. Therefore, tomato cultivars relatively rich in SER could be of interest for the tomato industry (Hano et al., 2017).

\section{Antioxidants evaluation}

Nowadays, several features, such as being rich in nutrients or having physiological benefits, are searched in foods. Among these, antioxidant compounds are the most interesting nutrients for human health, and are considerably present in fruits and vegetables (Dudonné et al., 2009). Moreover, these compounds are widely used to evaluate food quality. The hydrophilic and lipophilic fractions were examined to evaluate antioxidants in new tomato cultivars.

TPC assay was chosen to quantify phenolics' content in hydrophilic fraction, essential components of antioxidant compounds in tomatoes (Fanasca et al., 2006). The antioxidant activity was also tested by two different in vitro anti-radical assays-ABTS and DPPH (Campestrini et al., 2019). Moreover, these two radicals are sensitive to different types of antioxidants. Consequently, their combined use consented to an effective evaluation of antioxidant activity.

The results and significant differences are shown in Table 3. For TPC, Sugarland had the highest results with $303.15 \pm 21.62 \mathrm{mg}$ GAE$/ \mathrm{kg}$, followed by Dulcemiel and Bamano (256.39 \pm 6.63 and $242.18 \pm 6.6 \mathrm{mg} \mathrm{GAE} / \mathrm{kg}$, respectively). TPC results were in accordance with previously reported tomato results, especially for cherry tomatoes (Raffo et al., 2002; Riga et al., 2016). 
Table 3. Quantitative results of evaluation of antioxidants in tomato samples. Samples not connected by the same letter are significantly different.

\begin{tabular}{lccccc} 
& Bamano & Dulcemiel & Sugarland & $\begin{array}{c}\text { Control } \\
\text { fresh }\end{array}$ & $\begin{array}{c}\text { Control } \\
\text { canning }\end{array}$ \\
\hline TPC $(\mathrm{mg} \mathrm{GAE} / \mathrm{kg})$ & $242.18^{\mathrm{d}} \pm 6.60$ & $256.39^{\mathrm{d}} \pm 6.63$ & $303.15^{\mathrm{c}} \pm 21.62$ & $369.98^{\mathrm{b}} \pm 12.37$ & $458.97^{\mathrm{a}} \pm 3.11$ \\
DPPH $(1 \%)$ & $88.61^{\mathrm{b}} \pm 3.42$ & $93.38^{\mathrm{a}} \pm 3.47$ & $91.25^{\mathrm{a}} \pm 1.36$ & $93.46^{\mathrm{a}} \pm 1.34$ & $92.04^{\mathrm{a}} \pm 0.74$ \\
ABTS $(1 \%)$ & $60.34^{\mathrm{b}} \pm 1.92$ & $26.63^{\mathrm{d}} \pm 1.54$ & $32.50^{\mathrm{c}} \pm 2.49$ & $96.82^{\mathrm{a}} \pm 0.29$ & $98.64^{\mathrm{a}} \pm 0.38$ \\
TCC $(\mathrm{mg} \mathrm{BCE} / \mathrm{kg})$ & $40.12^{\mathrm{c}} \pm 2.69$ & $33.12^{\mathrm{d}} \pm 0.99$ & $54.12^{\mathrm{b}} \pm 1.36$ & $142.00^{\mathrm{a}} \pm 5.05$ & $143.17^{\mathrm{a}} \pm 4.99$ \\
Lycopene $(\mathrm{mg} / \mathrm{kg})$ & $29.25^{\mathrm{c}} \pm 7.48$ & $12.12^{\mathrm{d}} \pm 1.25$ & $48.88^{\mathrm{b}} \pm 2.95$ & $127.80^{\mathrm{a}} \pm 1.79$ & $128.50^{\mathrm{a}} \pm 1.38$
\end{tabular}

TPC: total phenolic content; TCC: total carotenoids content; DPPH: 2,2-diphenyl-1-picrylhydrazyl; ABTS: diammonium salt; GAE: gallic acid equivalent.

The trend of TPC results agreed with DPPH radical scavenging assay for antioxidant activity, proving a high radical inhibition by the three cultivars. The lowest result was achieved by Bamano cultivar (88.61, I\%). A similar result was reported by $\mathrm{Lu}$ et al. (2020), who established that TPC values could be positively correlated with the DPPH values ( $\mathrm{Lu}$ et al., 2020). However, Bamano variety had demonstrated the highest ABTS scavenging activity results (60.34, I\%), followed by Sugarland (32.50, I\%) and Dulcemiel variety (26.63, I\%). In Bamano samples, these results could be explained by a more significant presence of other chemical compounds with antioxidant activity not included in the phenolic compounds, such as vitamin $C$ or anthocyanins (Pataro et al., 2015; Marengo et al., 2017).

Total carotenoids and lycopene contents were evaluated in the lipophilic fraction of antioxidants by UV-Vis methods. Among new cultivars, Sugarland had the highest content of carotenoids (54.12 $\pm 1.36 \mathrm{mg} \mathrm{BCE} / \mathrm{kg}$ ) and lycopene $(48.88 \pm 2.95 \mathrm{mg} / \mathrm{kg})$, followed by Bamano $(40.12 \pm 2.69 \mathrm{mg} \mathrm{BCE} / \mathrm{kg}, 29.25 \pm 7.48 \mathrm{mg} / \mathrm{kg})$ and Dulcemiel (33.12 $\pm 0.99 \mathrm{mg} \mathrm{BCE} / \mathrm{kg}, 12.12 \pm 1.25 \mathrm{mg} / \mathrm{kg}$ ). These values of compounds in new tomato cultivars were compared with the literature data (D'Evoli et al., 2013). It is also appropriate to highlight that lycopene is the major carotenoid in cherry tomatoes, representing $40-90 \%$ of the total carotenoid contents in new cultivars.

The values obtained were significantly lower than that of control, except for DPPH assay results for Sugarland and Dulcemiel cultivars.

\section{Multivariate analysis}

Different profiles of bioactive compounds found in tomatoes had suggested the hypothesis that some of the compounds detected for quality and safety assessment could also be typical of a cultivar (Uarrota et al., 2014). Therefore, their presence as a potential authenticity marker of the tomato variety was investigated (Bajoub et al., 2016). For this purpose, PCA and CA were used to explore data matrices in order to highlight a natural grouping among samples (Marengo et al., 2017). Autoscaling pretreatment was conducted in the data matrix composed of experimental results (Nur Azira et al., 2014). The PCA results are reported in Figure 3: Sugarland is represented by circles, Bamano by squares, Dulcemiel by crosses, control fresh by stars, and control canning by triangles. In PCA, the first two principal components (PC1 and PC2) accounted for $82.9 \%$ of the total variability (Liu et al., 2013). In the scores plot, all cultivars were clearly separated (Šamec et al., 2016). New cultivars are located in the left part of the diagram, Sugarland and Dulcemiel in the upper part, while Bamano in the lower one. Control cultivars were located on the right, fresh cultivar samples on the top, and the canning ones on the lower part. As highlighted by the scores plot, PC1 differentiated new cultivars (Sugarland, Bamano, and Dulcemiel) from the control. This PC was highly influenced by physicochemical properties $(\mathrm{pH}$ and SSC), carotenoids (including lycopene), phenolic compounds, and SPD and TYR for BAs. Separation among each cultivar was enabled by PC2, whereby BAs (SER, $\mathrm{BAI}, \mathrm{HIS}$, and $\beta$-PEA) and DPPH anti-radical assays were the major contributors.

To characterize new cultivars, PCA was recalculated by excluding control cultivars. The scores and loadings' plot of this analysis are given in Figure 4.

The loadings' plot pointed out for Dulcemiel samples was positively correlated with DPPH, SPD, and HIS variables. It is clear in Tables 2 and 3 that Dulcemiel cultivar had the highest content in these compounds. Sugarland demonstrated a positive correlation with SER, BAI, PUT, TPC, SSC, total carotenoids, and lycopene. Moreover, Sugarland had a high negative correlation with SPM. Samples of the Bamano cultivar were positively correlated with CAD, $\beta$-PEA, $\mathrm{pH}$, and ABTS content. Therefore, 
(A)

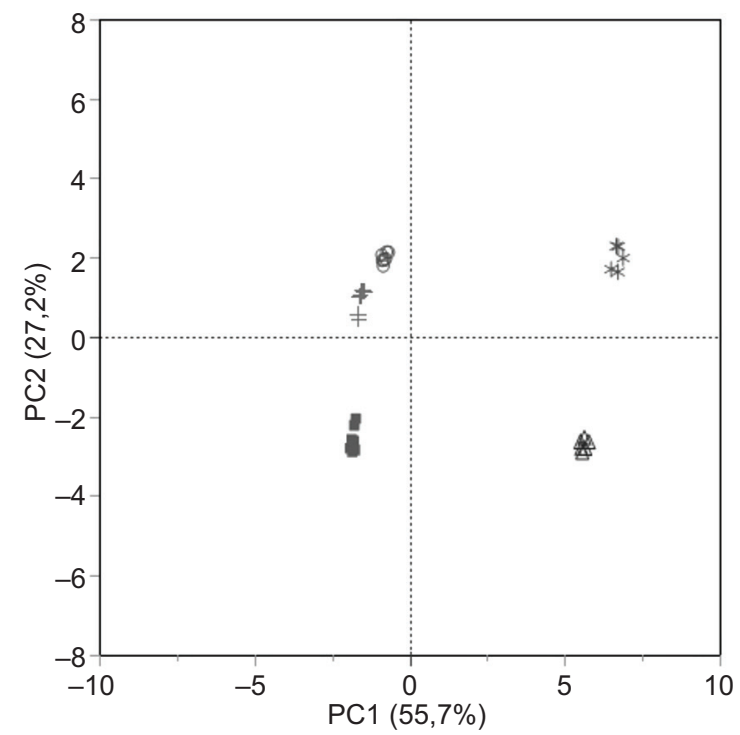

(B)

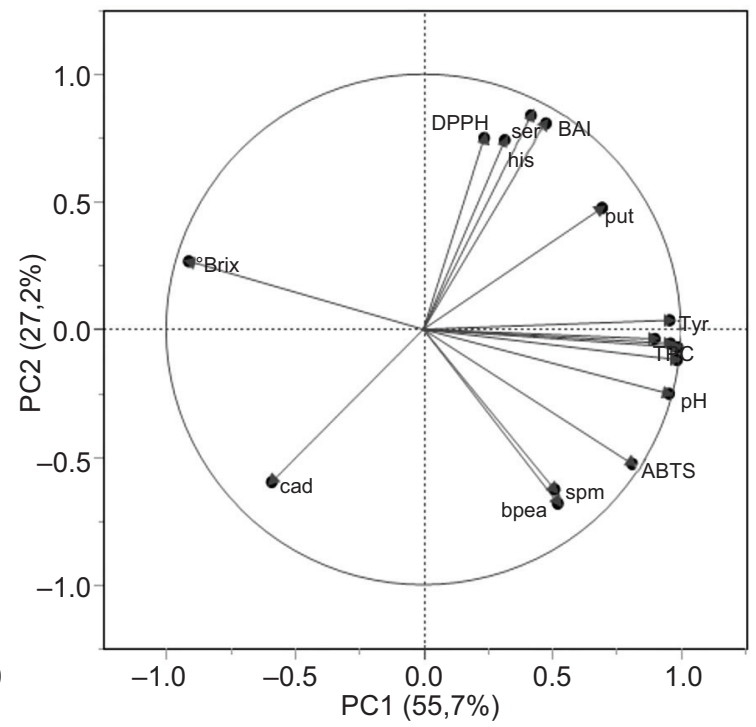

Figure 3. (A) Principal components analysis (PCA) scores and (B) loading plots of tomato samples: Sugarland (circles), Bamano (squares), Dulcemiel (crosses), control fresh (stars), control canning (triangles).

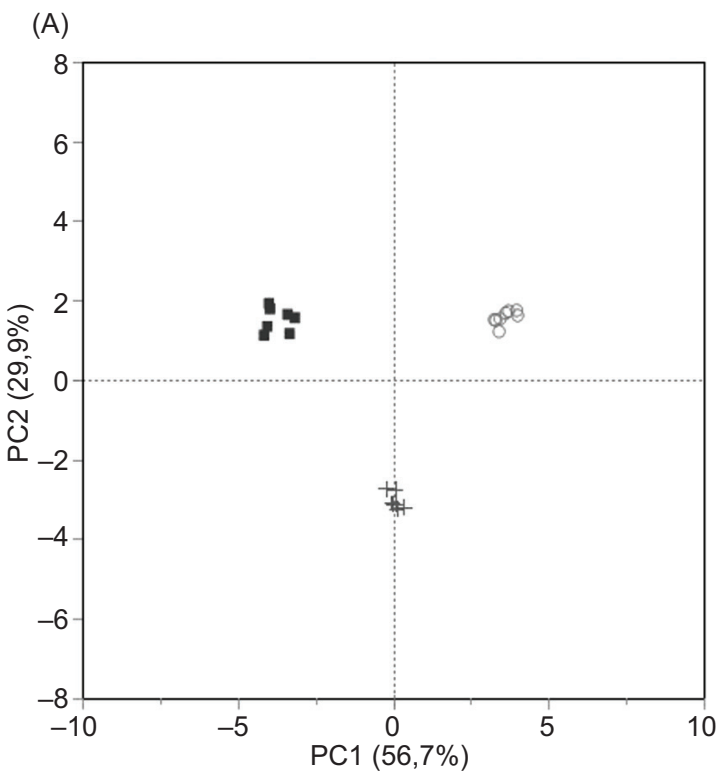

Figure 4. (A) Principal components analysis (PCA) scores and Bamano (squares), and Dulcemiel (crosses).

results of the $\mathrm{PC}$ explorative analysis were in accordance with the experimental ones (Guerreiro et al., 2013).

The good results of PCA analysis were also confirmed by CA, reported in Figure 5. This analysis pointed out general similarities or differences in the profile of bioactive compounds of the investigated cultivars. The first level of dendrogram demonstrates two clusters: the first one comprises control cultivars, and the second one by three new cultivars (Bamano, Dulcemiel, and Sugarland). At

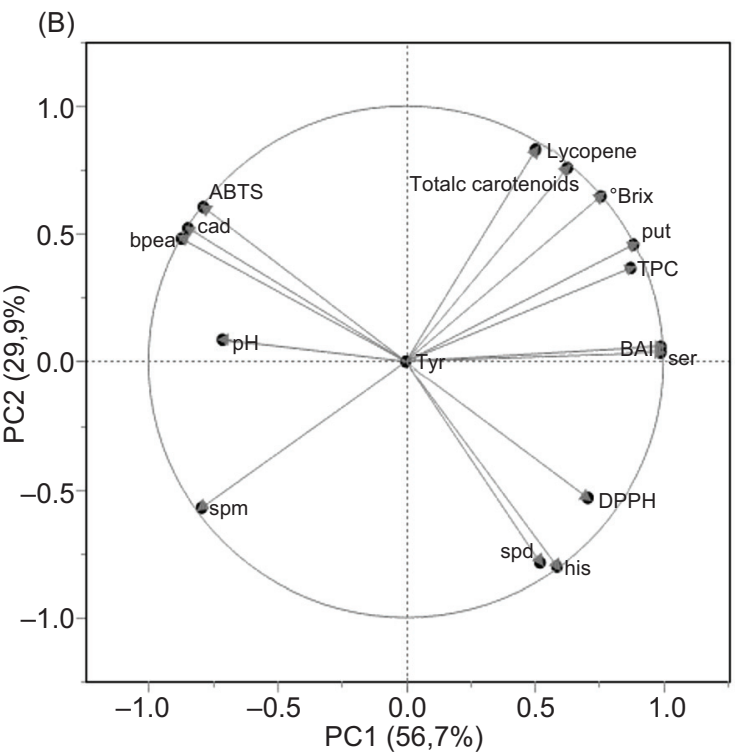

(B) loading plots of tomato samples: Sugarland (circles), the lower level of dendrogram, the first cluster is divided in two parts by separating control cultivars as the samples used for fresh market and that for canning industry. The second cluster (three new cultivars) was also divided into two parts: the first part consisting of Bamano samples, and the other one comprising Dulcemiel and Sugarland samples. Therefore, these two cultivars exhibited similar contents to the compounds examined herein. CA and PCA results demonstrated differentiation among new cultivars and the control. 


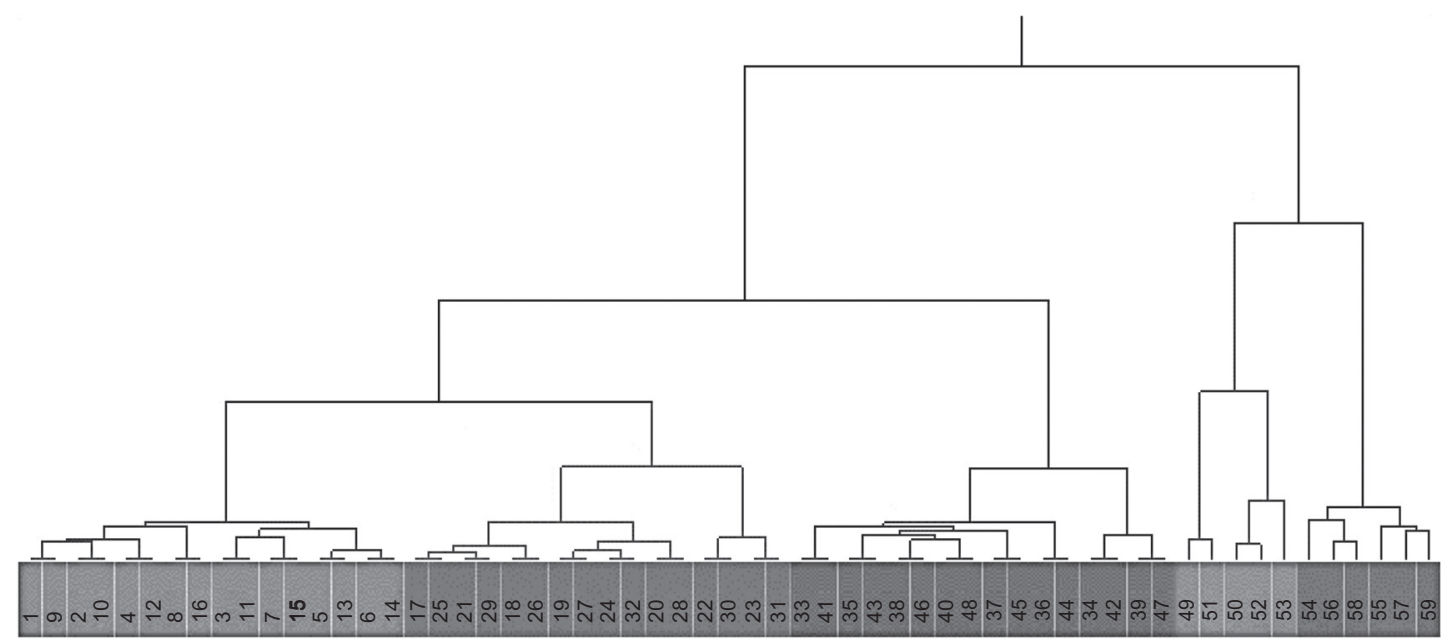

Figure 5. Cluster analysis: Sugarland (samples 1-16), Dulcemiel (samples 17-32), Bamano (samples 33-48), control fresh (samples 49-53), and control canning (samples 54-59).

\section{Conclusion}

This study assessed the quality and safety of three new cherry tomato cultivars through bioactive compounds evaluation. All the samples came from the same Italian region to minimize differences because of production factors (e.g., climate, soil, etc.). BAs and antioxidant fractions were investigated in Bamano, Dulcemiel, and Sugarland varieties, besides evaluation of physicochemical characteristics. The results were also compared with two control cultivars usually involved in the fresh market and canning industry. The new cultivars had meager amount of HIS $(<\mathrm{LOQ} 0.57 \pm 0.02 \mathrm{mg} / \mathrm{kg})$ and TYR $(<\mathrm{LOQ})$ as well as an interesting amount of SER $(132.47 \pm 2.05 \mathrm{mg} / \mathrm{kg}-266.87 \pm 11.16 \mathrm{mg} / \mathrm{kg})$. Therefore, quality features were assessed in addition to the absence of spoilage indicators. The antioxidant evaluation was conducted by TPC, anti-radical assays, and total carotenoids and lycopene contents. Comparison with control cultivars demonstrated different physicochemical properties, lower content in total BAs, and lower antioxidant compounds. Finally, a chemometric evaluation of bioactive compounds was conducted by PCA and CA. Different profiles of analyzed compounds enabled a successful differentiation of new cultivars and the control. Therefore, the chosen bioactive compounds resulted in suitable markers for quality and safety assessment of analyzed samples. However, this research could be a good start for new possible investigations. Each variety needs additional experimentation for full characterization of antioxidant fraction and a shelf-life study to evaluate the post-harvest decay. An interesting aspect could be the application and assessment of these tomatoes in processed products.

\section{Conflict of interest}

The authors declare that they have no conflict of interest in the subject matter or materials discussed in this manuscript.

\section{References}

Al Bulushi I., Poole S., Deeth H.C. and Dykes G.A. 2009. Biogenic amines in fish: roles in intoxication, spoilage, and nitrosamine formation-a review. Crit. Rev. Food. Sci. Nutr. 49(4):369. https:// doi.org/10.1080/10408390802067514

Antolinos V., Sánchez-Martínez M.J., Maestre-Valero J.F., LópezGómez A. and Martínez-Hernández G.B. 2020. Effects of irrigation with desalinated seawater and hydroponic system on tomato quality. Water. 12(2):518. https://doi.org/10.3390/ w12020518

Armenta S. and de la Guardia M. 2016. Analytical approaches for the evaluation of food protected designation of origin. In: Espiñeira, M. and Santaclara, F.J. (eds.), Advances in food traceability techniques and technologies - improving quality throughout the food chain. Woodhead, Sawston, Cambridgeshire, Ch. 15, pp. 275-301. https://doi.org/10.1016/B978-0-08-100310-7.00015-6

Bajoub A., Ajal E.A., Fernández-Gutiérrez A. and CarrascoPancorbo A. 2016. Evaluating the potential of phenolic profiles as discriminant features among extra virgin olive oils from Moroccan controlled designations of origin. Food. Res. Int. 84:41. https://doi.org/10.1016/j.foodres.2016.03.010

Campestrini L.H., Melo P.S., Peres L.E.P., Calhelha R.C., Ferreira I.C.F.R. and Alencar S.M. 2019. A new variety of purple tomato as a rich source of bioactive carotenoids and its potential health benefits. Heliyon. 5(11):e02831. https://doi.org/10.1016/j. heliyon.2019.e02831 
Carillo P., Kyriacou M.C., El-Nakhel C., Pannico A., dell'Aversana E., D'Amelia L., et al. 2019. Sensory and functional quality characterization of protected designation of origin 'Piennolo del Vesuvio' cherry tomato landraces from Campania-Italy. Food Chem. 292:166. https://doi.org/10.1016/j.foodchem.2019.04.056

Chiacchierini E., Restuccia D. and Vinci G. 2006. Evaluation of two different extraction methods for chromatographic determination of bioactive amines in tomato products. Talanta. 69(3):548. https://doi.org/10.1016/j.talanta.2005.10.027

Coyago-Cruz E., Corell M., Moriana A., Hernanz D., BenítezGonzález A.M., Stinco C.M., et al. 2018. Antioxidants (carotenoids and phenolics) profile of cherry tomatoes as influenced by deficit irrigation, ripening and cluster. Food Chem. 240:870. https://doi.org/10.1016/j.foodchem.2017.08.028

Dudonné S., Vitrac X., Coutiére P., Woillez M. and Mérillon J.M. 2009. Comparative study of antioxidant properties and total phenolic content of 30 plant extracts of industrial interest using DPPH, ABTS, FRAP, SOD, and ORAC assays. J. Agric. Food Chem. 57(5):1768. https://doi.org/10.1021/jf803011r

D'Evoli L., Lombardi-Boccia G., and Lucarini M. Influence of heat treatments on carotenoid content of cherry tomatoes. Foods. 2013 Sep; 2(3): 352-363. https://doi.org/10.3390/ foods 2030352

Fanasca S., Colla G., Maiani G., Venneria E., Rouphael Y., Azzini E., et al. 2006. Changes in antioxidant content of tomato fruits in response to cultivar and nutrient solution composition. J. Agric. Food Chem. 54(12):4319. https://doi.org/10.1021/jf0602572

Food and Agriculture Organization Corporate Statistical Database (FAOSTAT). 2019. Production of tomatoes: top 10 producers 2017. Available at: http://www.fao.org/faostat/en/\#data

Fratoddi I., Rapa M., Testa G., Venditti I., Scaramuzzo F.A. and Vinci G. 2018. Response surface methodology for the optimization of phenolic compounds extraction from extra virgin olive oil with functionalized gold nanoparticles. Microchem. J. 138:430. https://doi.org/10.1016/j.microc.2018.01.043

Giuggioli N.R., Sottile F. and Peano C. 2016. Quality indicators for modified atmosphere packaging (MAP) storage of high-quality European plum (Prunus domestica L.) cultivars. Ital. J. Food Sci. 28:376. https://doi.org/10.14674/1120-1770/ijfs.v38

Guerreiro J.S., Barros M., Fernandes P., Pires P. and Bardsley R. 2013. Principal component analysis of proteolytic profiles as markers of authenticity of PDO cheeses. Food Chem.136(34):1526. https://doi.org/10.1016/j.foodchem.2012.02.066

Handa A.K. and Mattoo A.K. 2010. Differential and functional interactions emphasize the multiple roles of polyamines in plants. Plant Physiol. Biochem. 48(7):540. https://doi.org/10.1016/j. plaphy.2010.02.009

Hano S., Shibuya T., Imoto N., Ito A., Imanishi S., Aso H., et al. Serotonin content in fresh and processed tomatoes and its accumulation during fruit development. Sci. Hortic. 214:107. https:// doi.org/10.1016/j.scienta.2016.11.009

Ingallina C., Maccelli A., Spano M., Di Matteo G., Di Sotto A., Giusti A.M., et al. 2020a. Chemico-biological characterization of torpedino di Fondi tomato fruits: a comparison with San Marzano cultivar at two ripeness stages. Antioxidants. 9(10):1027. https://doi.org/10.3390/antiox9101027
Ingallina C., Sobolev A.P., Circi S., Spano M., Fraschetti C., Filippi A., et al. 2020b. Cannabis Sativa L. inflorescences from monoecious cultivars grown in central Italy: an untargeted chemical characterization from early flowering to ripening. Molecules. 25(8):1908. https://doi.org/10.3390/molecules25081908

Ingallina C., Sobolev A.P., Circi S., Spano M., Giusti A.M. and Mannina L. 2020c. New hybrid tomato cultivars: an NMR-based chemical characterization. Appl. Sci. 10(5):1887. https://doi. org/10.3390/app10051887

Islam J., Shirakawa H., Nguyen T.K., Aso H. and Komai M. 2016. Simultaneous analysis of serotonin, tryptophan and tryptamine levels in common fresh fruits and vegetables in Japan using fluorescence HPLC. Food Biosci. 13:56. https://doi.org/10.1016/j. fbio.2015.12.006

Istituto Servizi Mercato Agricolo Alimentare. 2017. Report industrial tomatoes. Available at: http://www.ismea.it/flex/cm/pages/ ServeBLOB.php/L/IT/IDPagina/10110

Kalač P. 2014. Health effects and occurrence of dietary polyamines: a review for the period 2005-mid 2013. Food Chem.161:27. https://doi.org/10.1016/j.foodchem.2014.03.102

Linares D.M., Del Rio B., Redruello B., Ladero V., Martin M.C., Fernandez M., et al. 2016. Comparative analysis of the in vitro cytotoxicity of the dietary biogenic amines tyramine and histamine. Food Chem. 197(Pt A):658. https://doi.org/10.1016/j. foodchem.2015.11.013

Liu F.X., Fu S.F., Bi X.F., Chen F., Liao X.J., Hu X.S., et al. 2013. Physico-chemical and antioxidant properties of four mango (Mangifera indica L.) cultivars in China. Food Chem. 138(1):396. https://doi.org/10.1016/j.foodchem.2012.09.111

Liu H., Meng F., Chen S., Yin T., Hu S., Shao Z., et al. 2019. Ethanol treatment improves the sensory quality of cherry tomatoes stored at room temperature. Food Chem. 298:125069. https:// doi.org/10.1016/j.foodchem.2019.125069

Lu C., Ding J., Park H.K. and Feng H. 2020. High-intensity ultrasound as a physical elicitor affects secondary metabolites and antioxidant capacity of tomato fruits. Food Control. 113:107176. https://doi.org/10.1016/j.foodcont.2020.107176

Marengo E., Mazzucco E., Robotti E., Gosetti F., Manfredi M. and Calabrese G. 2017. Characterization study of tomato sauces stored in different packaging materials. Curr. Anal. Chem. 13(3):187. https://doi.org/10.2174/1573411012666160504125330

Masetti O., Ciampa A., Nisini L., Valentini M., Sequi P. and Dell'Abate M.T. 2014. Cherry tomatoes metabolic profile determined by $1 \mathrm{H}$-high resolution-NMR spectroscopy as influenced by growing season. Food Chem. 162:215. https://doi. org/10.1016/j.foodchem.2014.04.066

Nambeesan S., Datsenka T., Ferruzzi M.G., Malladi A., Mattoo A.K. and Handa AK. 2010. Overexpression of yeast spermidine synthase impacts ripening, senescence and decay symptoms in tomato. Plant J. 63(5):836. https://doi. org/10.1111/j.1365-313X.2010.04286.x

Nur Azira T., Che Man Y.B., Raja Mohd Hafidz R.N., Aina M.A. and Amin I. 2014. Use of principal component analysis for differentiation of gelatine sources based on polypeptide molecular weights. Food Chem.151:286. https://doi.org/10.1016/j. foodchem.2013.11.066 
Palomino-Vasco M., Acedo-Valenzuela M.I., RodríguezCáceres M.I. and Mora-Diez N. 2019. Automated chromatographic method with fluorescent detection to determine biogenic amines and amino acids. Application to craft beer brewing process. J. Chromatogr A.1601:155. https://doi. org/10.1016/j.chroma.2019.04.063

Pataro G., Sinik M., Capitoli M.M., Donsì G. and Ferrari G. 2015. The influence of post-harvest UV-C and pulsed light treatments on quality and antioxidant properties of tomato fruits during storage. Innov. Food. Sci. Emerg. Technol. 2015:103. https://doi. org/10.1016/j.ifset.2015.06.003

Peralta I. and Spooner D. 2014. History, origin and early cultivation of tomato (Solanaceae). In: Razdan M.K. and Matoo A.K. (eds.), Genetic improvement of solanaceous crop, Vol 2. Science Publishers, Enfiled, NH, pp. 1-24. https://doi.org/10.1201/ b10744-2

Preti R., Rapa M. and Vinci G. 2017. Effect of steaming and boiling on the antioxidant properties and biogenic amines content in green bean (Phaseolus vulgaris) varieties of different colours. J. Food. Qual. 2017:5329070. https://doi.org/10.1155/2017/5329070

Raffo A., Leonardi C., Fogliano V., Ambrosino P., Salucci M., Gennaro L., et al. 2002. Nutritional value of cherry tomatoes (Lycopersicon esculentum cv. Naomi F1) harvested at different ripening stages. J. Agric. Food Chem. 50(22):6550. https://doi. org/10.1021/jf020315t

Ramos R.M., Brandão P.F. and Rodrigues J.A. 2020. Development of a SALLE-HPLC-FLD analytical method for the simultaneous determination of ten biogenic amines in cheese. Food Anal. Methods.13:1088. https://doi.org/10.1007/s12161-020-01730-6

Riga P., Benedicto L., García-Flores L., Villaño D., Medina S. and Gil-Izquierdo Á. 2016. Rootstock effect on serotonin and nutritional quality of tomatoes produced under low temperature and light conditions. J. Food Compos. Anal. 46:50. https://doi. org/10.1016/j.jfca.2015.11.003
Šamec D., Maretić M., Lugarić I., Mešić A., Salopek-Sondi B. and Duralija B. 2016. Assessment of the differences in the physical, chemical and phytochemical properties of four strawberry cultivars using principal component analysis. Food Chem. 194:828. https://doi.org/10.1016/j.foodchem.2015.08.095

Sánchez-Pérez S., Comas-Basté O., Rabell-González J., VecianaNogués M., Latorre-Moratalla M. and Vidal-Carou M. 2018. Biogenic amines in plant-origin foods: are they frequently underestimated in low-histamine diets? Foods. 7(12):205. https://doi.org/10.3390/foods7120205

Selli S., Kelebek H., Ayseli M.T. and Tokbas H. 2014. Characterization of the most aroma-active compounds in cherry tomato by application of the aroma extract dilution analysis. Food Chem.165:540. https://doi.org/10.1016/j.foodchem.2014.05.147

Silla Santos M.H. 1996. Biogenic amines: their importance in foods. Int. J. Food Microbiol. 29(2-3):213. https://doi. org/10.1016/0168-1605(95)00032-1

Szabo K., Cătoi A.F. and Vodnar D.C. 2018. Bioactive compounds extracted from tomato processing by-products as a source of valuable nutrients. Plant Foods Hum. Nutr. 73(4):268. https:// doi.org/10.1007/s11130-018-0691-0

Tonolo F., Moretto L., Folda A., Scalcon V., Bindoli A., Bellamio M., et al. 2019. Antioxidant properties of fermented soy during shelf life. Plant Foods Hum. Nutr. 74(3):287. https://doi.org/10.1007/ s11130-019-00738-6

Uarrota V.G., Moresco R., Coelho B., Nunes E.D.C., Peruch L.A.M., Neubert E.D.O., et al. 2014. Metabolomics combined with chemometric tools (PCA, HCA, PLS-DA and SVM) for screening cassava (Manihot esculenta Crantz) roots during post-harvest physiological deterioration. Food Chem.161:67. https://doi. org/10.1016/j.foodchem.2014.03.110 